\title{
Adherence to guideline-recommended therapies among patients with diverse manifestations of vascular disease
}

This article was published in the following Dove Press journal:

Vascular Health and Risk Management

3 March 2015

Number of times this article has been viewed

\section{Debbie C Chen' \\ Ehrin J Armstrong ${ }^{2}$ \\ Gagan D Singh' \\ Ezra A Amsterdam' \\ John R Laird'}

'Department of Internal Medicine, Vascular Center and Division of Cardiovascular Medicine, University of California, Davis, Sacramento, CA USA; ${ }^{2}$ Division of Cardiology and VA Eastern Colorado Healthcare System, University of Colorado, Denver, CO, USA
Correspondence: John R Laird Medical Director of the Vascular Center, UC Davis Medical Center, 4860 Y Street, Suite 3400, Sacramento, CA 958I7, USA

$\mathrm{Tel}+\mathrm{I} 9167342028$

Fax + I 9167342030

Email john.laird@ucdmc.ucdavis.edu
Background: Current guidelines recommend aspirin, statins, angiotensin-converting enzyme inhibitors (ACEIs), and smoking abstinence for all patients with vascular disease. There is little data on the variation in adherence to guideline-recommended therapies among patients with different clinical manifestations of vascular disease.

Purpose: To analyze the variation in adherence to guideline-recommended therapies among patients with diverse manifestations of vascular disease.

Methods: We analyzed a comprehensive database of all patients with critical limb ischemia, claudication, acute limb ischemia, carotid artery stenosis, subclavian artery stenosis, renal artery stenosis, or mesenteric ischemia who underwent angiography between 2006 and 2013 at a multidisciplinary vascular center.

Results: Among 1,114 patients with vascular disease, adherence to guideline-recommended therapy at time of angiography included use of aspirin in 936 (84\%), statins in 753 (68\%), ACEIs in $673(60 \%)$, and smoking abstinence in $788(71 \%)$. A total of $335(30 \%)$ patients utilized all four guideline-recommended therapies. Adherence to four guideline-recommended therapies was lowest among patients with acute limb ischemia (14\%) and highest among patients with renal artery stenosis (37\%). Among all patients with vascular disease, the range of adherence to individual guidelines was $64 \%-91 \%$ for aspirin, $43 \%-83 \%$ for statins, $49 \%-66 \%$ for ACEIs, and $47 \%-78 \%$ for smoking abstention.

Conclusion: The majority of patients with diverse manifestations of vascular disease take aspirin and abstain from smoking while fewer patients are prescribed ACEIs and statins. Among the current recommendations, statins have the widest variation in adherence. Less than one-third of patients with diverse manifestations of vascular disease are prescribed all four guidelinerecommended therapies.

Keywords: peripheral arterial disease, secondary prevention, statin medications

\section{Introduction}

Patients with vascular disease have an increased risk for cardiovascular ischemic events, including myocardial infarction (MI), stroke, and death. ${ }^{1-5}$ Multiple studies have indicated that patients with vascular disease have the same or higher risk of long-term mortality as patients with coronary artery disease (CAD) ${ }^{6,7}$ Furthermore, an economic analysis of data from the Reduction of Atherothrombosis for Continued Health $(\mathrm{REACH})$ registry demonstrated that symptomatic peripheral artery disease (PAD) was associated with greater vascular-related hospitalization rates and associated costs than CAD. ${ }^{8}$ Current treatment guidelines established by the American College of Cardiology (ACC) and the American Heart Association (AHA) recommend aspirin, statin medications, angiotensin-converting enzyme (ACE) inhibitors, and smoking 
abstinence, as each of these interventions has been shown to reduce major adverse cardiovascular events in patients with vascular disease. ${ }^{9-11}$ Multiple studies have consistently shown that millions of patients with lower extremity PAD are undertreated..$^{12-15}$ There is little data, however, regarding the variation in adherence to guideline-recommended therapies among patients with different clinical manifestations of vascular disease, including mesenteric ischemia and renal, carotid, or subclavian artery stenoses. An analysis of rates of adherence to guideline-recommended therapies among patients with diverse manifestations of vascular disease may shed light on the variation in treatment for specific subgroups within this high-risk patient population and highlight potential opportunities to address disparities in patient care.

Our study objective was to assess the patterns of adherence to guideline-recommended therapies (aspirin, statin medications, ACE inhibitors, and smoking abstinence) among patients with different clinical manifestations of vascular disease and identify the specific guidelines that were least utilized among each patient subgroup. Because statin medications had the widest variation in usage, we also studied the differences in cholesterol levels among these patient subgroups. Suboptimal adherence to guidelines among individuals with vascular disease may contribute to high rates of preventable cardiovascular morbidity and mortality.

\section{Methods}

\section{Study design and data sources}

This study utilized data from the University of California, Davis, PAD and Carotid Disease Registry, which comprises all patients with a clinical diagnosis of PAD or carotid disease who underwent diagnostic angiography and/or therapeutic endovascular intervention at the University of California, Davis, Medical Center between June 1, 2006 and May 1, 2013. ${ }^{16}$ At the time of data extraction, the registry included 1,114 patients. The study protocol was approved by the Institutional Review Board at the University of California, Davis Medical Center.

\section{Study population and data collection}

All patients in the registry had vascular disease defined by critical limb ischemia (CLI), acute limb ischemia (ALI), claudication, mesenteric ischemia, and/or carotid artery, renal artery, or subclavian artery stenosis. The patient population consisted of individuals living primarily in Northern California or Nevada. All patients underwent diagnostic angiography or endovascular intervention at the UC Davis Medical Center.

Data collection for the registry was based on detailed electronic medical records and angiographic review.
Baseline demographic, clinical, laboratory, and procedural data were obtained through preprocedure clinical notes, admission history, and in-patient documentation. Comorbidities that may affect physician prescribing, including patient history of MI, stroke, CAD, and major bleeding, were also recorded. Medical prescribing patterns were verified by pharmacy prescriptions both preprocedure and during follow-up. All records were reviewed by trained chart abstractors and verified by a board-certified cardiologist.

\section{Data definitions}

The ACC/AHA guidelines have designated aspirin, statin medications, and smoking abstention as class I recommendations; ACE inhibitors are a class IIa recommendation for treatment of patients with vascular disease. ${ }^{9,11,17}$ Each patient's utilization of these four guideline-recommended therapies within 3 months preprocedure was assessed. Patients were categorized as adherent to a guideline-recommended therapy if their medication list and preprocedural clinic visit notes included: 1) aspirin; 2) statin medications; 3) ACE inhibitors or angiotensin receptor blockers; or 4) smoking abstinence. This definition of adherence therefore reflects a combination of both physician decision to prescribe the therapy (eg, prescription of an ACE inhibitor) and patient-reported adherence to that therapy (eg, self-report of ACE inhibitor use).

\section{Outcomes}

The primary outcome of the study was the frequency of adherence to each of the four guideline-recommended therapies among patients with diverse manifestations of vascular disease. Secondary outcomes included adherence to statin medications and its association with preprocedural cholesterol levels.

\section{Statistical analysis}

Clinical characteristics were described as numbers and percentages for categorical variables, and as means with standard deviations for continuous variables. Continuous variables were compared using the Wilcoxon rank sum test and categorical values using chi-squared or Fisher's exact tests. All data were analyzed using Stata Version 12.1 (StataCorp LP, College Station, TX). For all tests, a $P$-value $<0.05$ was considered significant.

\section{Results}

Among the cohort of 1,114 patients with vascular disease, 299 (27\%) presented with claudication, 386 (35\%) with CLI, 55 (5\%) with ALI, 207 (19\%) with carotid artery stenosis, 
$42(4 \%)$ with mesenteric ischemia, $90(8 \%)$ with renal artery stenosis, and 35 (3\%) with subclavian artery stenosis (Figure 1).

Baseline characteristics of patients at the time of angiography are summarized in Table 1. Patients who were adherent to all four guideline-recommended medications were on average older (mean age 69 versus 65 years, $P=0.001$ ) and were more likely to have a number of associated medical comorbidities, including congestive heart failure (CHF), diabetes (DM), hypertension (HTN), CAD, and a prior MI. Consistent with this high-risk profile, patients adherent to all four guideline-recommended therapies were also more likely to be prescribed other cardioprotective medications, including beta blockers and clopidogrel (Table 1).

\section{Baseline medication usage}

Overall adherence to guideline-recommended therapies at time of angiography included use of aspirin in 936 (84\%), statins in 753 (68\%), ACE inhibitors in 673 (60\%), and smoking abstinence in $788(71 \%)$ patients. In total, $335(30 \%)$ patients met all four guideline-recommended therapies. Patients with ALI had the lowest rate of four-guideline adherence at $14 \%$, while patients with renal artery stenosis had the highest rate at $37 \%$ (Table 2).

Among patients with diverse manifestations of vascular disease, the range of adherence to individual guideline-recommended therapies was 64\%-91\% for aspirin, $43 \%-83 \%$ for statins (Figure 2), 49\%-66\% for ACE inhibitors, and $47 \%-78 \%$ for smoking abstention. There was greatest variation in statin use despite a $68 \%$ rate of adherence to statins among all patients with vascular disease. Patients presenting with subclavian artery stenosis had the highest rates of aspirin (91\%) and statin (83\%) use while the mesenteric

\section{Diverse clinical manifestations of vascular disease}

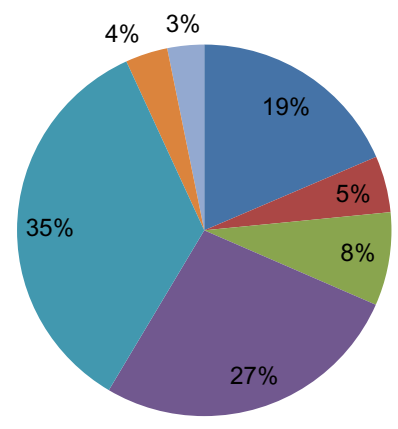

$$
\begin{aligned}
& \text { - Carotid artery stenosis } \\
& \text { - ALI } \\
& \text { Renal artery stenosis } \\
& \text { - Claudication } \\
& \text { - CLI } \\
& \text { Mesenteric ischemia } \\
& \text { - Subclavian artery stenosis }
\end{aligned}
$$

Figure I Population of patients with diverse clinical manifestations of vascular disease $(\mathrm{N}=I,|| 4)$.

Abbreviations: $\mathrm{ALI}$, acute limb ischemia; CLI, critical limb ischemia. ischemia group had the lowest ( $64 \%$ and $43 \%$, respectively). The claudication group had the highest rate of adherence to ACE inhibitors at $66 \%$ and the subclavian artery stenosis group had the lowest adherence rate at $49 \%$. Patients with renal artery stenosis were found to be most adherent (78\%) to smoking abstinence while patients with ALI were least adherent (47\%) (Table 2). Overall, the majority of patients with diverse manifestations of vascular disease were taking aspirin and abstaining from smoking while fewer patients were prescribed statins and ACE inhibitors.

\section{Association of adherence to statin medications with cholesterol levels}

Patients who were treated with a statin medication had lowdensity lipoprotein (LDL) levels ranging from $75 \pm 27 \mathrm{mg} / \mathrm{dL}$ in ALI to $96 \pm 30 \mathrm{mg} / \mathrm{dL}$ in carotid artery stenosis. In comparison, patients who were nonadherent to statin medications had LDL levels ranging from $92 \pm 43 \mathrm{mg} / \mathrm{dL}$ in mesenteric ischemia to $139 \pm 50 \mathrm{mg} / \mathrm{dL}$ in renal artery stenosis. On average, there was a $27 \mathrm{mg} / \mathrm{dL}$ difference in LDL between patients who were treated with statins versus those who were not. LDL levels in patients with renal artery stenosis and ALI were most affected by statin therapy, as there was a $48 \mathrm{mg} / \mathrm{dL}$ and 43 $\mathrm{mg} / \mathrm{dL}$ difference, respectively, between those who were statin adherent versus statin nonadherent. On the other hand, there was an $11 \mathrm{mg} / \mathrm{dL}$ difference in LDL levels between statinadherent and statin-nonadherent patients with mesenteric ischemia (Table 3 and Figure 3).

\section{Discussion}

The risk of major adverse cardiovascular events in individuals with peripheral artery disease is higher than the risk faced by patients with established CAD or cerebral vascular disease. ${ }^{7,18}$ While multiple studies have identified suboptimal use of secondary prevention in this high-risk population and have called for action to alleviate the clinical burden of vascular disease, ${ }^{15,19-21}$ this is to our knowledge the first study to examine the patterns of guideline adherence among patients with multiple different manifestations of vascular disease including claudication, CLI, ALI, mesenteric ischemia, and carotid, renal, or subclavian artery stenosis. Our analyses of these trends indicate that statin medications and ACE inhibitors were on average the guideline-recommended therapies that were least adhered to among patients with vascular disease, with adherence to statin medications being the most variable. We also found that patients with mesenteric ischemia and ALI were least adherent to all four of these recommended therapies. Multiple factors likely 
Table I Baseline characteristics of patients with vascular disease

\begin{tabular}{|c|c|c|c|c|}
\hline Variable & $\begin{array}{l}\text { Overall population } \\
(\mathrm{N}=1,1 \mid 4)\end{array}$ & $\begin{array}{l}4 \text { guideline therapies } \\
(\mathrm{N}=335)\end{array}$ & $\begin{array}{l}<\mathbf{4} \text { guideline therapies } \\
(\mathrm{N}=\mathbf{7 7 9})\end{array}$ & $P$-value \\
\hline Age, years & $66 \pm 11$ & $69 \pm 10$ & $65 \pm 13$ & 0.001 \\
\hline Male, n (\%) & $603(54)$ & $188(56)$ & $415(53)$ & 0.4 \\
\hline Race/ethnicity (\%) & & & & 0.007 \\
\hline Caucasian & $900(8 I)$ & $263(79)$ & $637(82)$ & \\
\hline Hispanic & $81(7)$ & $28(8)$ & $53(7)$ & \\
\hline African American & $70(6)$ & $29(8)$ & $4 \mathrm{I}(5)$ & \\
\hline Asian & $28(3)$ & $15(4)$ & $13(2)$ & \\
\hline $\mathrm{BMI}, \mathrm{kg} / \mathrm{m}^{2}$ & $27 \pm 6$ & $28 \pm 6$ & $27 \pm 6$ & 0.06 \\
\hline CHF, n (\%) & $24 \mid(22)$ & $93(28)$ & 148 (19) & 0.001 \\
\hline DM, n (\%) & $493(44)$ & $178(53)$ & $315(40)$ & $<0.001$ \\
\hline $\mathrm{GFR}, \mathrm{mL} / \mathrm{min}$ & $69 \pm 40$ & $65 \pm 34$ & $7 I \pm 43$ & 0.05 \\
\hline HTN, n (\%) & $952(85)$ & $321(96)$ & $631(8 I)$ & $<0.001$ \\
\hline CAD, n (\%) & $579(52)$ & $225(67)$ & $354(45)$ & $<0.001$ \\
\hline History of MI, n (\%) & $164(15)$ & $63(19)$ & $101(13)$ & 0.01 \\
\hline History of stroke/TIA, n (\%) & $243(22)$ & $60(18)$ & $183(23)$ & 0.04 \\
\hline History of malignancy, n (\%) & $156(14)$ & $36(11)$ & $120(15)$ & 0.04 \\
\hline COPD, n (\%) & $188(17)$ & $40(12)$ & $148(19)$ & 0.003 \\
\hline History of AAA, n (\%) & $48(4)$ & $15(4)$ & $33(4)$ & 0.9 \\
\hline History of Gl bleed, n (\%) & $57(5)$ & $12(4)$ & $45(6)$ & 0.1 \\
\hline History of prior amputation, $\mathrm{n}(\%)$ & $60(5)$ & $20(6)$ & $40(5)$ & 0.1 \\
\hline LDL, mg/dL & $90 \pm 38$ & $80 \pm 29$ & $94 \pm 40$ & 0.001 \\
\hline $\mathrm{HBA}_{\mathrm{Ic}}, \%$ & $7.7 \pm 2.1$ & $7.4 \pm 2.0$ & $7.8 \pm 2.1$ & 0.04 \\
\hline Beta blocker, n (\%) & $614(55)$ & $217(65)$ & $391(50)$ & $<0.001$ \\
\hline Clopidogrel, n (\%) & $635(57)$ & $218(65)$ & $417(54)$ & $<0.001$ \\
\hline $\mathrm{ABI}$ & $0.52 \pm 0.2$ & $0.53 \pm 0.24$ & $0.52 \pm 0.23$ & 0.5 \\
\hline
\end{tabular}

Abbreviations: AAA, abdominal aortic aneurysm; ABI, Ankle Brachial Index; BMI, body mass index; CAD, coronary artery disease; CHF, congestive heart failure; COPD, chronic obstructive pulmonary disease; DM, diabetes mellitus; GFR, glomerular filtration rate; GI, gastrointestinal; HBA ${ }_{1 c}$, hemoglobin $A_{1 \mathrm{c}}$; $\mathrm{HTN}_{\mathrm{N}}$, hypertension; LDL, lowdensity lipoprotein; MI, myocardial infarction; TIA, transient ischemic attack.

contribute to these observed variations among patients with diverse manifestations of vascular disease, including differences in physician and patient awareness of guideline therapies, potential for delay in diagnosis, and priorities of care. The data from this study enables us to further riskstratify patients with vascular disease and identify the specific disparities in patient care that may serve as the focus for continued efforts to improve secondary prevention and clinical outcomes.
In the last two decades, statins have become increasingly associated with improved survival and walking performance in patients with vascular disease. ${ }^{22-24}$ The Heart Protection Study Collaborative Group convincingly showed that $40 \mathrm{mg}$ daily of simvastatin significantly lowered risk of major vascular events compared to placebo, ${ }^{25}$ and later concluded that treatment with simvastatin is also cost-effective. ${ }^{26}$ Feringa et $\mathrm{al}^{27}$ demonstrated that higher doses of statins and lower LDL cholesterol levels were each independently associated

Table 2 Preprocedural adherence to guideline-recommended therapies

\begin{tabular}{|c|c|c|c|c|c|c|}
\hline \multirow{2}{*}{$\begin{array}{l}\text { Vascular disease } \\
\text { manifestation }\end{array}$} & \multirow[t]{2}{*}{$\mathbf{N}(\%)$} & \multicolumn{5}{|c|}{ Adherence to guideline-recommended therapies } \\
\hline & & $\begin{array}{l}\text { Aspirin, } \\
\text { n (\%) }\end{array}$ & $\begin{array}{l}\text { Statins, } \\
\text { n (\%) }\end{array}$ & $\begin{array}{l}\text { ACEI/ARBs, } \\
\text { n (\%) }\end{array}$ & $\begin{array}{l}\text { Smoking } \\
\text { abstinence, n (\%) }\end{array}$ & $\begin{array}{l}\text { All } 4 \text { guidelines, } \\
\text { n (\%) }\end{array}$ \\
\hline Claudication & $299(27)$ & $258(86)$ & $222(74)$ & $198(66)$ & 207 (69) & $108(36)$ \\
\hline CLI & $386(35)$ & $346(90)$ & $244(63)$ & $220(57)$ & $284(70)$ & $117(30)$ \\
\hline ALI & $55(5)$ & $38(69)$ & $29(53)$ & $28(5 \mathrm{I})$ & $26(47)$ & $8(14)$ \\
\hline Mesenteric ischemia & $42(4)$ & $27(64)$ & $18(43)$ & $25(60)$ & $31(74)$ & $8(19)$ \\
\hline Carotid artery stenosis & 207 (19) & $162(78)$ & $144(70)$ & $127(6 \mid)$ & $148(72)$ & $53(26)$ \\
\hline Renal artery stenosis & $90(8)$ & $73(81)$ & $67(74)$ & $58(64)$ & $70(78)$ & $33(37)$ \\
\hline Subclavian artery stenosis & $35(3)$ & $32(91)$ & $29(83)$ & $17(49)$ & $22(63)$ & $8(23)$ \\
\hline Total & $\mathrm{I}, \mathrm{I} \mid 4$ & $936(84)$ & $753(68)$ & $673(60)$ & $788(7 I)$ & $335(30)$ \\
\hline
\end{tabular}

Abbreviations: ACEI, angiotensin-converting enzyme inhibitors; ALI, acute limb ischemia; ARBs, angiotensin receptor blockers; CLI, critical limb ischemia. 


\section{Adherence to statin medications}

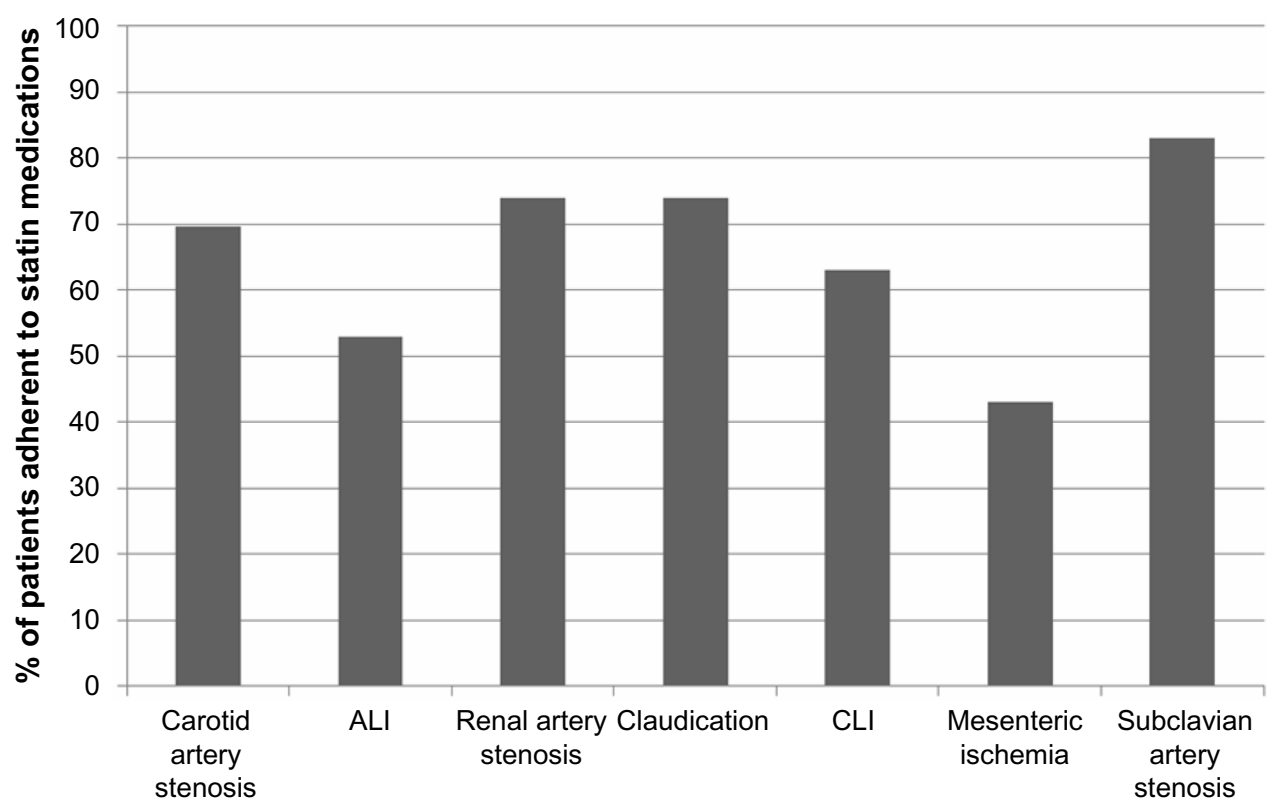

Figure 2 Adherence to statin medications among patients with diverse manifestations of vascular disease.

Abbreviations: $\mathrm{ALI}$, acute limb ischemia; $\mathrm{CLI}$, critical limb ischemia.

with lower all-cause mortality and cardiac death. The beneficial properties of statin medications may extend beyond their lipid-lowering effect to include atherosclerotic plaque stabilization, oxidative stress reduction, and a decrease in vascular inflammation. ${ }^{28}$ However, despite this overwhelming evidence of the efficacy of statins, studies consistently show that while trends in statin use have increased over time, patients with PAD continue to be undertreated. ${ }^{15,29}$ Subherwal et $\mathrm{al}^{15}$ reported a $56 \%$ statin use rate among patients with PAD and found that patients with PAD only were $20 \%$ less likely to use a statin in comparison to patients with CAD. Our study stratified the rates of statin usage among patients with seven different manifestations of vascular disease and identified patients presenting with mesenteric ischemia and ALI as the least adherent to statin medications. In 2010, statin prescription was identified as a core performance measure for treatment of patients with atherosclerotic occlusion of the aorta or lower extremities. ${ }^{10}$ Considering the variation in statin adherence that we have observed, future performance measures and awareness campaigns should establish the importance of statin therapy for patients with other manifestations of vascular disease as well. Identifying these disparities can serve as an important starting point in increasing guideline adherence in the general vascular disease population.

Importantly, we found that among patients with seven diverse manifestations of vascular disease, there was on average a $26 \mathrm{mg} / \mathrm{dL}$ difference in the LDL levels of patients who were adherent versus nonadherent to statin medications. Statin medications had the greatest observed association with decreased LDL in patients with ALI and renal artery stenosis. It is possible that larger differences in LDL could be due to more

Table 3 Preprocedural cholesterol levels among statin-adherent versus statin-nonadherent patients

\begin{tabular}{|c|c|c|c|c|c|c|c|c|}
\hline \multirow{2}{*}{$\begin{array}{l}\text { Vascular disease } \\
\text { manifestation }\end{array}$} & \multicolumn{4}{|c|}{ Statin adherent $(\mathrm{mg} / \mathrm{dL})$} & \multicolumn{4}{|c|}{ Statin nonadherent (mg/dL) } \\
\hline & TC & LDL & HDL & TG & TC & LDL & HDL & TG \\
\hline Claudication & $156 \pm 42$ & $89 \pm 37$ & $42 \pm 15$ & $128 \pm 63$ & $209 \pm 54$ & $118 \pm 43$ & $42 \pm 15$ & $132 \pm 63$ \\
\hline CLI & $|4| \pm 40$ & $75 \pm 27$ & $35 \pm 16$ & $162 \pm 80$ & $166 \pm 58$ & $95 \pm 40$ & $38 \pm 18$ & $133 \pm 80$ \\
\hline $\mathrm{ALI}$ & $142 \pm 40$ & $75 \pm 32$ & $37 \pm 10$ & $|4| \pm 92$ & $170 \pm 34$ & $118 \pm 32$ & $27 \pm 7$ & $137 \pm 52$ \\
\hline Mesenteric ischemia & $146 \pm 50$ & $81 \pm 37$ & $45 \pm 11$ & $135 \pm 43$ & $167 \pm 54$ & $92 \pm 43$ & $53 \pm 24$ & $102 \pm 32$ \\
\hline Carotid artery stenosis & $163 \pm 33$ & $96 \pm 30$ & $42 \pm 22$ & $132 \pm 72$ & $182 \pm 59$ & $113 \pm 55$ & $41 \pm 16$ & $162 \pm 120$ \\
\hline Renal artery stenosis & $158 \pm 38$ & $91 \pm 32$ & $4 I \pm 15$ & $139 \pm 90$ & $20 I \pm 60$ & $139 \pm 50$ & $37 \pm 14$ & $130 \pm 72$ \\
\hline Subclavian artery stenosis & $155 \pm 38$ & $92 \pm 32$ & $36 \pm 13$ & 321 & $227 \pm 35$ & $112 \pm 32$ & $51 \pm 13$ & $126 \pm 48$ \\
\hline
\end{tabular}

Abbreviations: ALI, acute limb ischemia; CLI, critical limb ischemia; HDL, high-density lipoprotein; LDL, low-density lipoprotein; TC, total cholesterol; TG, triglycerides. 


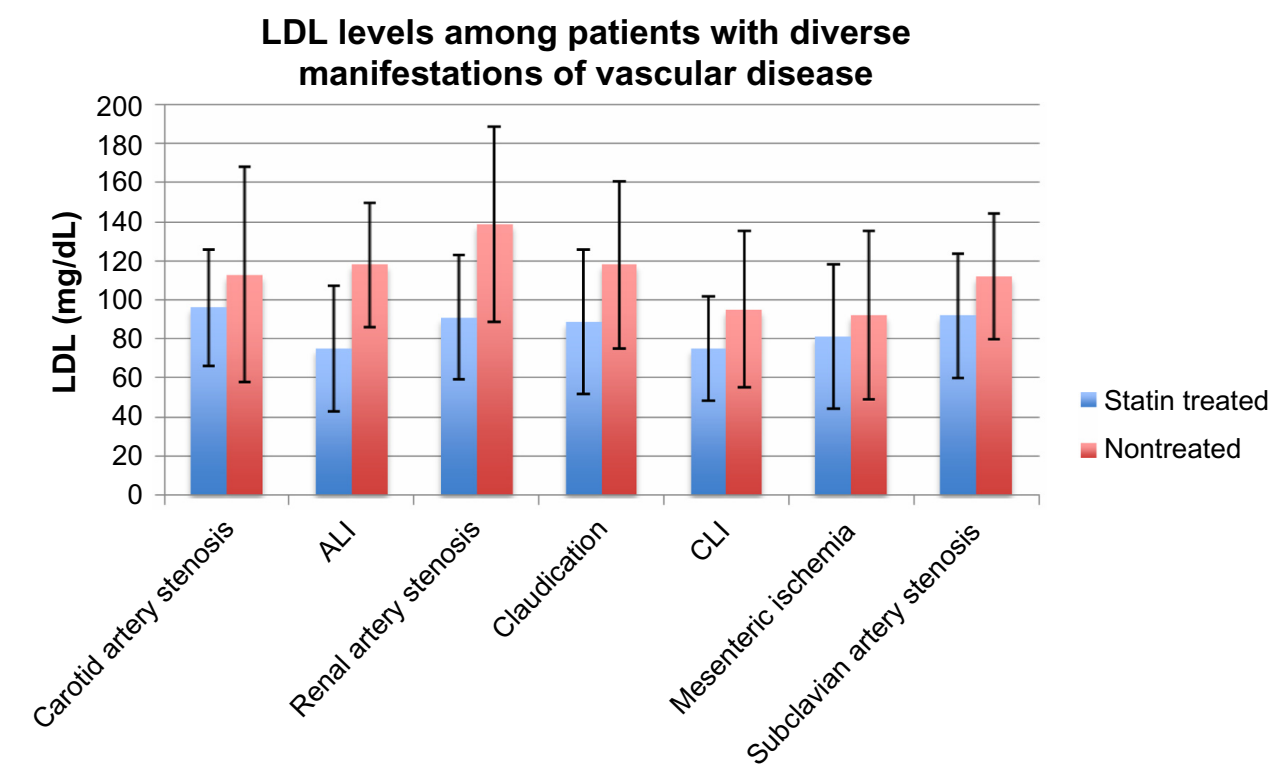

Figure 3 Association between statin adherence and LDL levels.

Note: Error bars represent the range of LDL levels for each subgroup of patients with vascular disease.

Abbreviations: ALI, acute limb ischemia; CLI, critical limb ischemia; LDL, low-density lipoprotein.

intensive statin therapy among certain subgroups of patients with vascular disease, although this is unlikely. Mean LDL levels may also be influenced by baseline cholesterol levels as well as LDL target levels. Considering the finding from the Heart Protection Study that a $1 \mathrm{mmol} / \mathrm{L}$ (38.61 mg/dL) difference in LDL was associated with a $24 \%$ reduction in relative risk of major vascular events, ${ }^{25}$ treatment with statins in patients with vascular disease severe enough to necessitate angiographic intervention is imperative. Given the recent updated ACC/ AHA guidelines, all patients in this study met criteria for statin prescription, regardless of their observed LDL level. ${ }^{30}$

Use of ACE inhibitors among all patients with vascular disease was $60 \%$, making ACE inhibitors the least utilized guideline-recommended therapy among the four assessed in this study. The Heart Outcomes Prevention Evaluation (HOPE) study found that in patients with symptomatic PAD, ramipril reduced risk of cardiovascular events by approximately $25 \% .{ }^{31}$ Of note, subgroups of patients in the HOPE study who had significant reductions in cardiovascular events included both those with and without HTN, suggesting that ramipril likely benefits many PAD patients with otherwise normal blood pressures. Despite the established association between ACE inhibitors and reduced rates of MI, stroke, and death among patients with vascular disease, ${ }^{9,31,32}$ the routine use of ACE inhibitors in this patient population is not yet common practice. As more evidence is collected regarding the cardioprotective role of ACE inhibitors and the positive effects that they may have on walking times in patients with vascular disease, ${ }^{33}$ focus should be placed on increasing adherence to this guideline-recommended therapy.

To evaluate overall adherence to guideline-recommended therapies, we analyzed rates of adherence to all four of the guidelines. We found that $30 \%$ of patients with diverse manifestations of vascular disease adhered to the four guidelines. Rates of adherence ranged from $14 \%$ and $19 \%$ in patients with ALI and mesenteric ischemia, respectively, to $36 \%$ and $37 \%$ in patients with claudication and renal artery stenosis, respectively. A number of studies have analyzed the additive effects of utilizing multiple guideline-recommended therapies in patients with vascular disease. In a study utilizing data from the National Health and Nutrition Examination Survey, Pande et $\mathrm{al}^{14}$ found that treatment with more than two preventive therapies (aspirin, statin, and/or ACE inhibitors) was associated with a $65 \%$ reduction in risk of all-cause mortality in patients with an ankle-brachial index $\leq 0.90$. Hoeks et al ${ }^{19}$ concluded that patients taking aspirin, statin medications, and beta-blockers at baseline had significantly lower 3-year mortality rates than patients who were nonadherent to these medical therapies. A more recent study by our group found that in patients with PAD severe enough to necessitate angiography, preprocedural adherence to aspirin, statins, ACE inhibitors, and smoking cessation was associated with a $36 \%$ reduction in major adverse cardiovascular events and $45 \%$ reduction in major adverse limb events over a 3 -year follow-up period. ${ }^{34}$ Furthermore, both Hoeks et al ${ }^{19}$ and our group $^{34}$ have demonstrated a graded relationship between 
greater use of guideline-recommended therapies and lower 3 -year mortality rates. The significant reductions in major adverse cardiovascular and limb events that these studies identified have important implications for the projected benefit that increased adherence to guideline-recommended therapies may have in this high-risk population. With the awareness that less than one-third of patients with vascular disease are fully adhering to recommended guidelines, and the knowledge that optimal adherence to guidelines is associated with improved long-term health outcomes, it has become increasingly important and feasible to make advances towards alleviating the clinical burden of vascular disease.

Patients who were being treated with all four guidelinerecommended therapies at the time of angiography had significantly more baseline comorbidities, including congestive heart failure, DM, HTN, CAD, and previous MI or stroke, than patients who were being treated with less than four guidelinerecommended therapies (Table 1). Taken together with the fact that guideline recommendations for these comorbidities and for vascular disease overlap, our results suggest that other cardiovascular comorbidities may be the main determinant of guideline adherence, rather than the specific manifestation of vascular disease. This is likely due to better national awareness of guidelines for treating diseases such as CAD or DM. These results further support the need for increased education and awareness to optimize guideline-recommended therapies for patients with vascular disease.

A number of successful quality improvement initiatives to improve guideline adherence have been implemented, including the ACC Guidelines Applied in Practice (GAP) and AHA Get With The Guidelines (GWTG) programs for the inpatient setting, and the more recently launched The Guideline Advantage (TGA) for the outpatient environment. ${ }^{35-37}$ The GAP and GWTG programs successfully utilized patient management tools, education, and quality indicators to improve guideline adherence in patients post-MI ${ }^{35,36}$ or post-ischemic stroke. ${ }^{38}$ TGA recently defined its strategic plan to implement functional data aggregation and analytics platforms to maximize adherence to evidence-based guidelines for the management of cancer, CAD, and DM. ${ }^{37}$ While nationwide programs have been developed for heart failure, CAD, stroke, and DM, a similar program for vascular disease has not yet been implemented. Increased adoption of performance measures for patients with vascular disease, as outlined by Olin et al, ${ }^{10}$ together with extending nation-wide quality improvement initiatives to patients with diverse manifestations of vascular disease will be key to galvanizing a sustainable translation of best evidence into real-world clinical practice.

\section{Limitations}

This study should be interpreted in the context of its design. First, it is a retrospective investigation from a single center; therefore, patterns of care and disease may differ at other clinical sites. Second, although physician- and patientreported adherence to guideline-recommended therapies was thoroughly assessed through review of prescription records and clinical chart notes, absolute adherence could not be fully assessed. Third, inherent to all observational studies without randomization is the limitation that reported associations may not represent causality. Fourth, while the preprocedural clinical documentation included thorough reporting of patients' use of each of the guideline-recommended therapies, we did not have data regarding potential reasons for nonadherence (eg, contraindications).

\section{Conclusion}

This study demonstrated that less than one-third of patients with vascular disease manifesting as claudication, CLI, ALI, mesenteric ischemia, and carotid, renal, or subclavian artery stenosis are prescribed all four guideline-recommended therapies. The majority of patients with diverse manifestations of vascular disease take aspirin and abstain from smoking while fewer patients are prescribed statins and ACE inhibitors. Among these four recommendations, adherence to statin medications varied the most. These results help increase understanding of the variation in adherence to guideline-recommended therapies and highlight an important potential opportunity to improve quality of care for the highrisk population of vascular disease patients as a whole.

\section{Disclosure}

John R Laird reports being a consultant for Boston Scientific, Covidien, Abbott, Bard, and Medtronic. Ehrin J Armstrong reports being a consultant for Abbott Vascular and Spectranetics. All other authors report no conflicts of interest in this work.

\section{References}

1. Criqui MH. Peripheral arterial disease - epidemiological aspects. Vasc Med. 2001;6(3 Suppl):3-7.

2. Saw J, Bhatt DL, Moliterno DJ, et al. The influence of peripheral arterial disease on outcomes: a pooled analysis of mortality in eight large randomized percutaneous coronary intervention trials. $J$ Am Coll Cardiol. 2006;48(8):1567-1572.

3. Criqui MH, Langer RD, Fronek A, et al. Mortality over a period of 10 years in patients with peripheral arterial disease. $N$ Engl $J$ Med. 1992;326(6):381-386.

4. Criqui MH, Ninomiya JK, Wingard DL, Ji M, Fronek A. Progression of peripheral arterial disease predicts cardiovascular disease morbidity and mortality. J Am Coll Cardiol. 2008;52(21):1736-1742. 
5. Fowkes FG, Price JF, Stewart MC, et al. Aspirin for prevention of cardiovascular events in a general population screened for a low ankle brachial index: a randomized controlled trial. JAMA. 2010;303(9):841-848.

6. McDermott MM, Mehta S, Ahn H, Greenland P. Atherosclerotic risk factors are less intensively treated in patients with peripheral arterial disease than in patients with coronary artery disease. J Gen Intern Med. 1997;12(4):209-215.

7. Welten GM, Schouten O, Hoeks SE, et al. Long-term prognosis of patients with peripheral arterial disease: a comparison in patients with coronary artery disease. J Am Coll Cardiol. 2008;51(16):1588-1596.

8. Mahoney EM, Wang K, Keo HH, et al. Vascular hospitalization rates and costs in patients with peripheral artery disease in the United States. Circ Cardiovasc Qual Outcomes. 2010;3(6):642-651.

9. Hirsch AT, Haskal ZJ, Hertzer NR, et al. ACC/AHA 2005 Practice Guidelines for the management of patients with peripheral arterial disease (lower extremity, renal, mesenteric, and abdominal aortic): a collaborative report from the American Association for Vascular Surgery/Society for Vascular Surgery, Society for Cardiovascular Angiography and Interventions, Society for Vascular Medicine and Biology, Society of Interventional Radiology, and the ACC/AHA Task Force on Practice Guidelines (Writing Committee to Develop Guidelines for the Management of Patients With Peripheral Arterial Disease): endorsed by the American Association of Cardiovascular and Pulmonary Rehabilitation; National Heart, Lung, and Blood Institute; Society for Vascular Nursing; TransAtlantic Inter-Society Consensus; and Vascular Disease Foundation. Circulation. 2006;113(11):e463-e654.

10. Olin JW, Allie DE, Belkin M, et al. ACCF/AHA/ACR/SCAI/SIR/SVM/ SVN/SVS 2010 performance measures for adults with peripheral artery disease: a report of the American College of Cardiology Foundation/ American Heart Association Task Force on performance measures, the American College of Radiology, the Society for Cardiac Angiography and Interventions, the Society for Interventional Radiology, the Society for Vascular Medicine, the Society for Vascular Nursing, and the Society for Vascular Surgery (Writing Committee to Develop Clinical Performance Measures for Peripheral Artery Disease). Circulation. 2010;122(24):2583-2618.

11. Smith SC Jr, Benjamin EJ, Bonow RO, et al. AHA/ACCF secondary prevention and risk reduction therapy for patients with coronary and other atherosclerotic vascular disease: 2011 update: a guideline from the American Heart Association and American College of Cardiology Foundation endorsed by the World Heart Federation and the Preventive Cardiovascular Nurses Association. J Am Coll Cardiol. 2011;58(23):2432-2446.

12. Hirsch AT, Criqui MH, Treat-Jacobson D, et al. Peripheral arterial disease detection, awareness, and treatment in primary care. JAMA. 2001;286(11):1317-1324.

13. Ardati AK, Kaufman SR, Aronow HD, et al. The quality and impact of risk factor control in patients with stable claudication presenting for peripheral vascular interventions. Circ Cardiovasc Interv. 2012;5(6):850-855.

14. Pande RL, Perlstein TS, Beckman JA, Creager MA. Secondary prevention and mortality in peripheral artery disease: National Health and Nutrition Examination Study, 1999 to 2004. Circulation. 2011;124(1):17-23.

15. Subherwal S, Patel MR, Kober L, et al. Missed opportunities: despite improvement in use of cardioprotective medications among patients with lower-extremity peripheral artery disease, underuse remains. Circulation. 2012;126(11):1345-1354.

16. McCoach CE, Armstrong EJ, Singh S, et al. Gender-related variation in the clinical presentation and outcomes of critical limb ischemia. Vasc Med. 2013;18(1):19-26.

17. Smith SC Jr, Allen J, Blair SN, et al. AHA/ACC guidelines for secondary prevention for patients with coronary and other atherosclerotic vascular disease: 2006 update: endorsed by the National Heart, Lung, and Blood Institute. Circulation. 2006;113(19):2363-2372.

18. Steg PG, Bhatt DL, Wilson PW, et al. One-year cardiovascular event rates in outpatients with atherothrombosis. JAMA. 2007;297(11):1197-1206.

19. Hoeks SE, Scholte op Reimer WJ, van Gestel YR, et al. Medication underuse during long-term follow-up in patients with peripheral arterial disease. Circ Cardiovasc Qual Outcomes. 2009;2(4):338-343.
20. Mukherjee D, Lingam P, Chetcuti S, et al. Missed opportunities to treat atherosclerosis in patients undergoing peripheral vascular interventions: insights from the University of Michigan Peripheral Vascular Disease Quality Improvement Initiative (PVD-QI2). Circulation. 2002;106(15):1909-1912.

21. Cacoub PP, Abola MT, Baumgartner I, et al. Cardiovascular risk factor control and outcomes in peripheral artery disease patients in the Reduction of Atherothrombosis for Continued Health (REACH) Registry. Atherosclerosis. 2009;204(2):e86-e92.

22. McDermott MM, Guralnik JM, Greenland P, et al. Statin use and leg functioning in patients with and without lower-extremity peripheral arterial disease. Circulation. 2003;107(5):757-761.

23. Giri J, McDermott MM, Greenland P, et al. Statin use and functional decline in patients with and without peripheral arterial disease. $J \mathrm{Am}$ Coll Cardiol. 2006;47(5):998-1004.

24. Mohler ER 3rd, Hiatt WR, Creager MA. Cholesterol reduction with atorvastatin improves walking distance in patients with peripheral arterial disease. Circulation. 2003;108(12):1481-1486.

25. Heart Protection Study Collaborative Group. MRC/BHF Heart Protection Study of cholesterol lowering with simvastatin in 20,536 high-risk individuals: a randomised placebo-controlled trial. Lancet. 2002;360(9326):7-22.

26. Heart Protection Study Collaborative Group. Statin cost-effectiveness in the United States for people at different vascular risk levels. Circ Cardiovasc Qual Outcomes. 2009;2(2):65-72.

27. Feringa HH, Karagiannis SE, van Waning VH, et al. The effect of intensified lipid-lowering therapy on long-term prognosis in patients with peripheral arterial disease. J Vasc Surg. 2007;45(5):936-943.

28. Moreno PR, Fuster V. The year in atherothrombosis. J Am Coll Cardiol. 2004;44(11):2099-2110.

29. Westin GG, Armstrong EJ, Bang H, et al. Association between statin medications and mortality, major adverse cardiovascular event, and amputation-free survival in patients with critical limb ischemia. $J \mathrm{Am}$ Coll Cardiol. 2014;63(7):682-690.

30. Stone NJ, Robinson JG, Lichtenstein AH, et al. 2013 ACC/AHA Guideline on the treatment of blood cholesterol to reduce atherosclerotic cardiovascular risk in adults: a report of the American College of Cardiology/American Heart Association Task Force on Practice Guidelines. Circulation. 2014;129(25 Suppl 2):S1-S45.

31. Yusuf S, Sleight P, Pogue J, Bosch J, Davies R, Dagenais G. Effects of an angiotensin-converting-enzyme inhibitor, ramipril, on cardiovascular events in high-risk patients. The Heart Outcomes Prevention Evaluation Study Investigators. $N$ Engl J Med. 2000;342(3):145-153.

32. Feringa HH, van Waning VH, Bax JJ, et al. Cardioprotective medication is associated with improved survival in patients with peripheral arterial disease. J Am Coll Cardiol. 2006;47(6):1182-1187.

33. Ahimastos AA, Walker PJ, Askew C, et al. Effect of ramipril on walking times and quality of life among patients with peripheral artery disease and intermittent claudication: a randomized controlled trial. JAMA. 2013;309(5):453-460.

34. Armstrong EJ, Chen DC, Westin GG, et al. Adherence to guidelinerecommended therapy is associated with decreased major adverse cardiovascular events and major adverse limb events among patients with peripheral arterial disease. J Am Heart Assoc. 2014;3(2):e000697.

35. Mehta RH, Montoye CK, Gallogly M, et al. Improving quality of care for acute myocardial infarction: The Guidelines Applied in Practice (GAP) Initiative. JAMA. 2002;287(10):1269-1276.

36. Lewis WR, Peterson ED, Cannon CP, et al. An organized approach to improvement in guideline adherence for acute myocardial infarction: results with the Get With The Guidelines quality improvement program. Arch Intern Med. 2008;168(16):1813-1819.

37. Bufalino V, Bauman MA, Shubrook JH, et al. Evolution of "the guideline advantage": lessons learned from the front lines of outpatient performance measurement. Circ Cardiovasc Qual Outcomes. 2014;7(3):493-498.

38. Schwamm LH, Fonarow GC, Reeves MJ, et al. Get With the GuidelinesStroke is associated with sustained improvement in care for patients hospitalized with acute stroke or transient ischemic attack. Circulation. 2009;119(1):107-115. 
Vascular Health and Risk Management

Dovepress

\section{Publish your work in this journal}

Vascular Health and Risk Management is an international, peerreviewed journal of therapeutics and risk management, focusing on concise rapid reporting of clinical studies on the processes involved in the maintenance of vascular health; the monitoring, prevention and treatment of vascular disease and its sequelae; and the involvement of metabolic disorders, particularly diabetes. This journal is indexed on PubMed Central and MedLine. The manuscript management system is completely online and includes a very quick and fair peer-review system, which is all easy to use. Visit http://www.dovepress.com/ testimonials.php to read real quotes from published authors.

Submit your manuscript here: http://www.dovepress.com/vascular-health-and-risk-management-journal 